\title{
Behavior and injury in urban and rural adolescents
}

Anne W Riley, Sion Kim Harris, Margaret E Ensminger, Sheryl Ryan, Cheryl Alexander, Bert Green, Barbara Starfield

\begin{abstract}
Objectives-This study investigates the consistency of factors associated with adolescent injury in separate urban and rural samples.
\end{abstract}

Samples-Adolescents, 11-17 years old, in public schools in urban and rural Maryland $(n=2712)$.

Methods-Separate bivariate and logistic regression analyses were conducted for each sample to determine individual and environmental factors associated with major and minor injuries experienced in the previous year.

Results-Multivariate analyses revealed that, for both samples, the probability of a major injury was highest for boys and, among both boys and girls, for those who played several team sports. Among rural youth, other significant covariates of both major and minor injuries were a tendency to engage in risky behavior and to use alcohol. For urban youth, being white, carrying a weapon for protection, attending an unsafe school, and working for pay were also significant covariates. Interactions were important and complex.

Conclusions - The consistency of predictive factors, such as multiple sports team participation and risky and aggressive behaviors in completely different physical environments, underscores the need to address the contexts of heightened injury risk that some adolescents create wherever they live by playing sports and/ or behaving in an antisocial, aggressive manner. Moreover, the perception of lack of safety in schools and neighborhoods is associated with increased injury rates, suggesting the need for policy interventions to target social environments as well as behavior.

(Injury Prevention 1996; 2: 266-273)

Keywords: adolescents, sports, weapons, risk behavior.

Adolescents are the only group for whom the 1990 US national mortality reduction goals were not achieved. The rate of fatal adolescent injuries actually increased, accounting for $57^{\circ}$ \% of all deaths among youth $10-14$ years old and $79^{\circ}$, among $15-19$ year olds. ${ }^{12}$ Annually, 17800 adolescents die from injuries and more than a third incur an injury that requires medical attention or reduces activity for one day or more.${ }^{134}$ For every fatal injury, there are between 21 and 44 hospitalizations and a much larger number that require ambulatory medical care or result in dysfunction..$^{5-7}$ While the increase in fatalities due to intentional injuries from homicide and suicide is alarming, they account for fewer than one quarter of all adolescent deaths due to injury.

Factors that are associated with injury in very different populations are likely to be robust indicators of the mechanisms of injury occurrence in this age group. Although national rates of injury occurrence do not vary greatly between metropolitan and nonmetropolitan areas, adolescents in rural areas are reported to have much higher death rates. ${ }^{38}$ For example, the predominantly white populations of adolescents (including Hispanics) living in rural western states have mortality rates due to injuries consistently higher than those in the ethnically diverse states in the Northeast. ${ }^{9}$ Similarly, youth in North Carolina have higher mortality rates from injuries than those in the much less rural state of Massachusetts, 3.20 and 2.55 deaths per 10000 child years, respectively. ${ }^{10}$ However, the extent to which this reflects a difference in the incidence of injury is not clear because mortality rates also reflect differences in access to trauma centers. Although living in a rural area does not mean being on a farm, it is worth noting that there is a disproportionately high rate of serious and fatal injuries among adolescents and children living on farms. ${ }^{11} 12$

In contrast, prevailing media images of urban violence suggest that inner city youth are at highest risk of injury. In Maryland, for example, young people living in Baltimore have much higher rates of violent deaths than those in rural areas of the state. ${ }^{13}$ This perspective is supported by a national study of 112 communities in which the average adolescent in high density urban environments was more likely to engage in several high injury risk activities such as fighting, using alcohol or drugs, or skipping school, than those in any other type of community. ${ }^{14}$ These apparently contradictory findings suggest a need to better understand the relationship between serious injury and the environments, urban or rural, in which adolescents live.

Adolescent behavior and developmental status have recently been shown to be strongly related to injury, especially among rural youth. ${ }^{1516}$ In this study our intent was to examine the characteristics of the individuals, their behaviors, activities or immediate behavioral contexts, and their environmental factors, and to relate these to the occurrence of major and minor injuries using an integrated, 
multivariate approach. ${ }^{17}$ The study involves self reported injuries among youth living in an inner city urban environment or in rural communities, using data from a health status questionnaire completed in school. We hypothesized that despite fundamental differences in environment, the factors associated with injury would be similar in each sample, and that patterns of behavior would be more strongly related to injury than sociodemographic or personal characteristics.

\section{Methods}

\section{STUDY POPULATIONS}

This study involves adolescents in public schools in two different communities in Maryland, one urban and one rural. The urban sample was selected using an age stratified, random selection from all students in a middle school and a grade stratified random selection of science classrooms in a high school, both in Baltimore. The rural Maryland sample involved the entire student bodies of four schools in one county in the Appalachian region of Maryland (two middle and two high schools). The combined samples included 2712 respondents in grades $6-12$. In the urban sites the majority of the students were AfricanAmericans $\left(83.5^{\circ}{ }_{0}\right)$, while in the rural sites the majority were white $\left(99 \cdot 3^{\circ}{ }_{0}\right)$. Both samples involved students who were mostly from families in the middle to low socioeconomic status range. The families in the urban sample were more likely than those in the rural area to have a child receiving free or reduced cost lunches at school $\left(36^{\circ}{ }_{0} v 29^{\circ}{ }_{0}\right)$ and more likely to have a mother who graduated from college $\left(40^{\circ}{ }_{0} v 23^{\circ}{ }_{0}\right)$, reflecting a wider range of socioeconomic status in this sample. The rural teens represent those in an entire county, in which the largest two towns had populations of less than 2000 in $1990 .{ }^{18}$ The urban high school served academically successful youth living in the city, providing a sample that is similar in comprehensiveness to the rural sample. In the total sample, age was evenly distributed within the categories of $10-13$ years, $14-15$ years, and $16+$ years $\left(33 \cdot 0^{\circ}{ }_{0}, 34 \cdot 2^{\circ}{ }_{0}\right.$, and $32 \cdot 7^{\circ}$, respectively). Gender was also evenly distributed $\left(49.9^{\circ}\right.$ o girls). These distributions are similar within each of the samples (table 1).

\section{DATA COLLECTION}

Before administering the questionnaire in the schools, parents were mailed materials from the principals and the researcher explaining the survey and asking for their support. In Baltimore and western Maryland, response rates

Table 1 Samples by school status and sex

\begin{tabular}{lllllll}
\hline & \multicolumn{2}{l}{ Middle schools } & \multicolumn{3}{l}{ High schools } & \\
\cline { 2 - 3 } & Boys & Girls & & Boys & Girls & Total \\
\hline Rural & 338 & 336 & 615 & 558 & 1847 \\
Urban & 135 & 144 & 265 & 321 & 865 \\
Total & 473 & 480 & 880 & 879 & 2712 \\
\hline
\end{tabular}

were $88^{\circ}{ }_{\circ}$ and $89^{\circ}{ }_{\circ}$ respectively, with nonrespondents equally divided between absences and refusals. During the subsequent week in Baltimore, students were asked to complete a second survey, using similar procedures, to examine test-retest stability.

A comprehensive health status instrument was administered, the Child Health and Illness Profile-Adolescent Edition (CHIP-AE $\left.{ }^{\mathrm{m}}\right),{ }^{1920}$ for which higher scores indicate higher levels of the measured construct. Respondents reported on their somatic and emotional symptoms; well being; perception of health and self; acute and chronic illnesses; achievement in school; peer and family involvement; tendency to take risks; specific behaviors that pose a risk to health; delinquent behaviors that threaten achievement; involvement in health promoting behavior; and injuries experienced in the past year, as well as whether each injury required medical attention.

Injuries were classified as major or minor, consistent with the abbreviated injury severity rating system. ${ }^{21}$ Major injuries include head injuries or concussions; stab or gunshot wounds; and broken bones, noses, or dislocated joints. Examples of minor injuries were: a bad cut; a bad sprain or torn ligament; animal or human bite; and a bad burn. The mechanism of the injury was not known except when it was defined by the type of injury (for example, gunshot or stab wound). Information was not available on whether injuries resulted from intentional acts. If both a major and minor injury was reported, each was tabulated. Thus some youth are included in the major and minor injury groups.

A one year recall period was used for reporting injuries in the CHIP-AE ${ }^{\mathrm{tm}}$ to provide enough time for sufficient injuries to have occurred while ensuring reasonable accuracy of recall. ${ }^{22}{ }^{23}$ To examine the reliability of the reports, we examined the one week test-retest stability in a subsample of 365 respondents. Agreement between the two reports on the occurrences of any minor injury is $\kappa=0.51$ and for any major injury is $\kappa=0.47$ (Cohen's $\kappa$ values in the range of $0 \cdot 40-0 \cdot 75$ indicate good agreement). ${ }^{2425}$

All reports of injuries, whether medically treated or not, were included in these analyses. This approach avoids the bias associated with differential access to medical care when only medically treated injuries are included. Seventy per cent of urban students reported having a usual source of medical care, whereas only $51^{\circ}{ }_{0}$ of rural students reported similar access to care. This difference may explain the fact that youth in the rural area had a higher rate of all injuries but a lower rate of treated minor injuries. ${ }^{26}$ However, this was not observed for major injuries; rural youth had both more treated and untreated major injuries.

\section{MEASURES}

The following factors (independent variables) were assessed to determine their relationship to prior injury. The sociodemographic factors age, gender, socioeconomic, and for the urban 
sample, race - were predicted to have no association with injury once the influence of behavioral and environmental factors were accounted for. Disorders and impairments based on a medical diagnosis included emotional/ mental problem, behavior problem, epilepsy, hearing and vision disorders. These disorders may cause impairment in self regulation, ability to perceive danger, motor coordination, or response time, and were expected to be associated with higher rates of injury.

Several scales and items reflect behaviors engaged in by adolescents. The subdomains of the CHIP-AE ${ }^{\mathrm{tm}}$, threats to achievement, the five item adolescent risk taking scale, ${ }^{27}$ academic performance, and problem solving were used. These scales have been shown to have internal consistency coefficients between $0.78-0.83$ in multiple samples. ${ }^{20}$ The threats to achievement scale includes delinquent type behavior problems which, like the tendency to take risks, was expected to be associated with higher rates of injury. Better academic performance, and a proactive problem solving style, were expected to be protective. The 'weaponcarrying' item was extracted from the threats to achievement subdomain and examined separately.

Other specific behaviors that may increase exposure to injury risk were: participation on three or more sports teams in the past year; working for pay; ever driving a car; ever riding motorcycles/all terrain vehicles; ever drinking alcohol; carrying a weapon for protection; and infrequent recent use of seatbelts. Test-retest stability for these items ranged from a $\kappa$ of 0.48 to $0 \cdot 60$.

Environmental characteristics related to injury used CHIP-AE ${ }^{\mathrm{tm}}$ items about curfew on school nights, guns in the home, ratings of school and neighborhood safety, and family involvement and family safety and health. Other home influences included paternal and maternal education and the presence of one or two parents in the family. The behavior of friends was assessed using the subdomain peer influences. This characterizes the proportion of each adolescent's social network who uses drugs or alcohol or engages in sexual activity.

DATA ANALYSIS

Bivariate analyses were conducted to determine the association of each measured factor to major

Table 2 Prevalence (\%) of injuries in adolescents 11-17 years old by site and gender

\begin{tabular}{|c|c|c|c|c|c|c|}
\hline & \multicolumn{3}{|c|}{ Rural $(n=1847)$} & \multicolumn{3}{|c|}{ Urban $(n=865)$} \\
\hline & Boys & Girls & Total & Boys & Girls & Total \\
\hline Any injury & $67 \cdot 4$ & $61 \cdot 9$ & $64 \cdot 7$ & $61 \cdot 2$ & $45 \cdot 7$ & $52 \cdot 9$ \\
\hline Any major injury & 21.9 & $10 \cdot 0$ & $16 \cdot 1$ & $17 \cdot 3$ & $7 \cdot 6$ & $12 \cdot 2$ \\
\hline \multicolumn{7}{|l|}{ Major injuries } \\
\hline $\begin{array}{l}\text { Broken bone or nose, dis- } \\
\text { located joint }\end{array}$ & $17 \cdot 2$ & $7 \cdot 6$ & $12 \cdot 5$ & $10 \cdot 0$ & 4.5 & $7 \cdot 2$ \\
\hline Head injury or concussion & $6 \cdot 7$ & $2 \cdot 5$ & $4 \cdot 7$ & $6 \cdot 6$ & 2.9 & $4 \cdot 7$ \\
\hline \multirow{2}{*}{\multicolumn{7}{|c|}{ Minor injuries }} \\
\hline & & & & & $27 \cdot 8$ & \\
\hline Bad sprain or torn ligament & $26 \cdot 2$ & 23.9 & $25 \cdot 0$ & $24 \cdot 0$ & $12 \cdot 2$ & $17 \cdot 8$ \\
\hline Bad burn & $12 \cdot 8$ & $12 \cdot 4$ & $12 \cdot 6$ & $7 \cdot 4$ & 9.9 & 8.9 \\
\hline Animal or human bite & $11 \cdot 0$ & $9 \cdot 3$ & $10 \cdot 2$ & $11 \cdot 6$ & 8.9 & $10 \cdot 1$ \\
\hline
\end{tabular}

and minor injury. These analyses were done separately for the urban and rural sites. Logistic regression models ${ }^{28}$ were then constructed to determine the probability of incurring any injury using all the independent variables and interaction terms, entered simultaneously into the model. The final model reflects the contribution of all retained factors (variables), controlling for the contribution of all others. Potential interaction effects of the significant main effects were also examined.

\section{Results}

PREVALENCE OF MINOR AND MAJOR INJURIES Table 2 shows that a higher proportion of rural than urban youth suffered at least one major or one minor injury. Boys had higher rates than girls, and rural boys had the highest rates of all.

Table 3 shows the proportion of persons in each sample with a particular characteristic, and the proportion of those with each characteristic who had a major and a minor injury. The statistical tests are all within sample between the higher and lower risk categories, never between rural and urban. The characteristics (factors) are organized within categories: demographics, individual characteristics, behaviors and environment. For example, considering the first factor in behavior, risk taking, table 3 shows two contrasts based on the quartiles of the distribution. The first contrast shows that the $29 \cdot 2 \%$ of the rural group scored in the highest (worst) $25 \%$ of the distribution on this scale, whereas only $16.2 \%$ of the urban scored in this range. The rural group has only $17 \%$ in the lowest risk category, and $38 \%$ of the urban group are low risk takers. Of the rural youth in the highest risk quartile, almost $28 \%$ have incurred a major injury in the past year whereas this was true of only about $8 \%$ of those low on risk taking. For urban youth, $19 \%$ of the high risk takers incurred a major injury and only $6.4 \%$ of the low risk takers did so. The differences are not so startling for minor injuries. The CHIP-AE ${ }^{\mathrm{tm}}$ subdomain scores (academic performance, problem solving, threats to achievement, peer influences, and home safety, and health) are displayed in table 3 in a dichotomous form to indicate the percentage of injured youth who had high or low scores on the subdomains shown.

With the exception of age, school grade, father's education, and the socioeconomic indicators, all other factors were significantly related to at least one type of injury at one of the sites at the $p<0.05$ level. Table 3 includes only factors significant at $p<0.01$ because of the multiple comparisons.

FACTORS RELATED TO MAJOR INJURY IN MULTIVARIATE LOGISTIC REGRESSION ANALYSIS Factors that increase the probability of major injury, according to logistic regression analyses for both rural and urban sites, are summarized in tables 4 and 5. The odds ratios shown are adjusted for all main and interaction effects. 
Rural sample: major injury

The main effects and interaction terms are shown separately in tables 4 and 5 respectively. Only one main effect, gender, did not interact with another factor. Rural males were twice as likely to incur a major injury as girls. The other effects, a tendency to take risks and ever using alcohol, are important in terms of their interac- tions with participation on three or more sports terms. High and moderate risk taking tendencies increase the risk of major injury among those who play several sports, by 7.6 and 5.0 times, respectively, relative to those who do not take risks and do not play many sports (see table 5). This indicates the multiplicative effect of being a risk taker and playing many sports.

Table 3 Rates of major and minor injuries, conditional on factors significantly related to injury in the rural and urban samples ${ }^{\star}$

\begin{tabular}{|c|c|c|c|c|c|c|}
\hline & \multicolumn{3}{|l|}{ Rural group } & \multicolumn{3}{|l|}{ Urban group } \\
\hline & $\%$ of total & $\begin{array}{l}\text { Major injury } \\
(\%)\end{array}$ & $\begin{array}{l}\text { Minor injury } \\
(\%)\end{array}$ & $\%$ of total & $\begin{array}{l}\text { Major injury } \\
(\%)\end{array}$ & $\begin{array}{l}\text { Minor injury } \\
(\%)\end{array}$ \\
\hline $\begin{array}{l}\text { Total samples } \\
\text { Demographics }\end{array}$ & $100 \cdot 0$ & $16 \cdot 1$ & $58 \cdot 1$ & $100 \cdot 0$ & $12 \cdot 2$ & $46 \cdot 3$ \\
\hline $\begin{array}{l}\text { Gender } \\
\text { Male } \\
\text { Female }\end{array}$ & $\begin{array}{l}51 \cdot 9 \\
48 \cdot 1\end{array}$ & $\begin{array}{l}21 \cdot 9 \star \star \\
10 \cdot 0\end{array}$ & $\begin{array}{l}60 \cdot 2 \dagger \\
55 \cdot 8\end{array}$ & $\begin{array}{l}46 \cdot 4 \\
53 \cdot 6\end{array}$ & $\begin{array}{l}17 \cdot 3 \star \star \\
7 \cdot 6\end{array}$ & $\begin{array}{l}53 \cdot 8^{\star \star} \\
39 \cdot 6\end{array}$ \\
\hline $\begin{array}{l}\text { Race } \\
\text { White/other } \\
\text { Black }\end{array}$ & $\begin{array}{r}99 \cdot 3 \\
0 \cdot 7\end{array}$ & - & $\overline{-}$ & $\begin{array}{l}16 \cdot 5 \\
83 \cdot 5\end{array}$ & $\begin{array}{l}20 \cdot 3^{\star \star} \\
10 \cdot 6\end{array}$ & $\begin{array}{l}59 \cdot 4 \ddagger \\
43 \cdot 7\end{array}$ \\
\hline
\end{tabular}

Non-significant factors that were tested are: age, grade, number of adults in home, father's education, welfare, food stamps, Medicaid, and free/reduced cost lunch. An additional demographic factor significant at the $p<0.05$ level is: mother's education

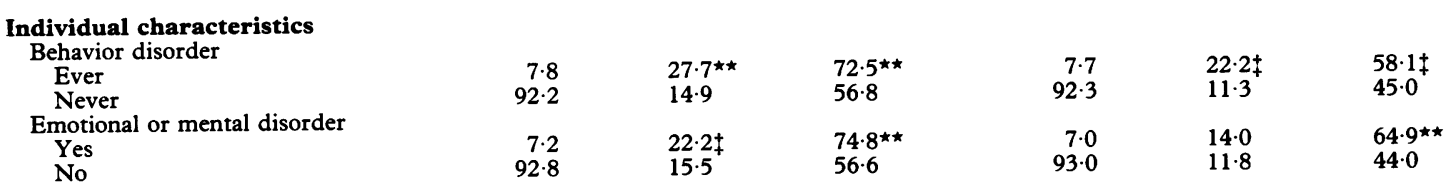

Additional individual characteristics significant at only the $\mathrm{p}<0.05$ level are: learning disability, hearing impairment, and vision impairment

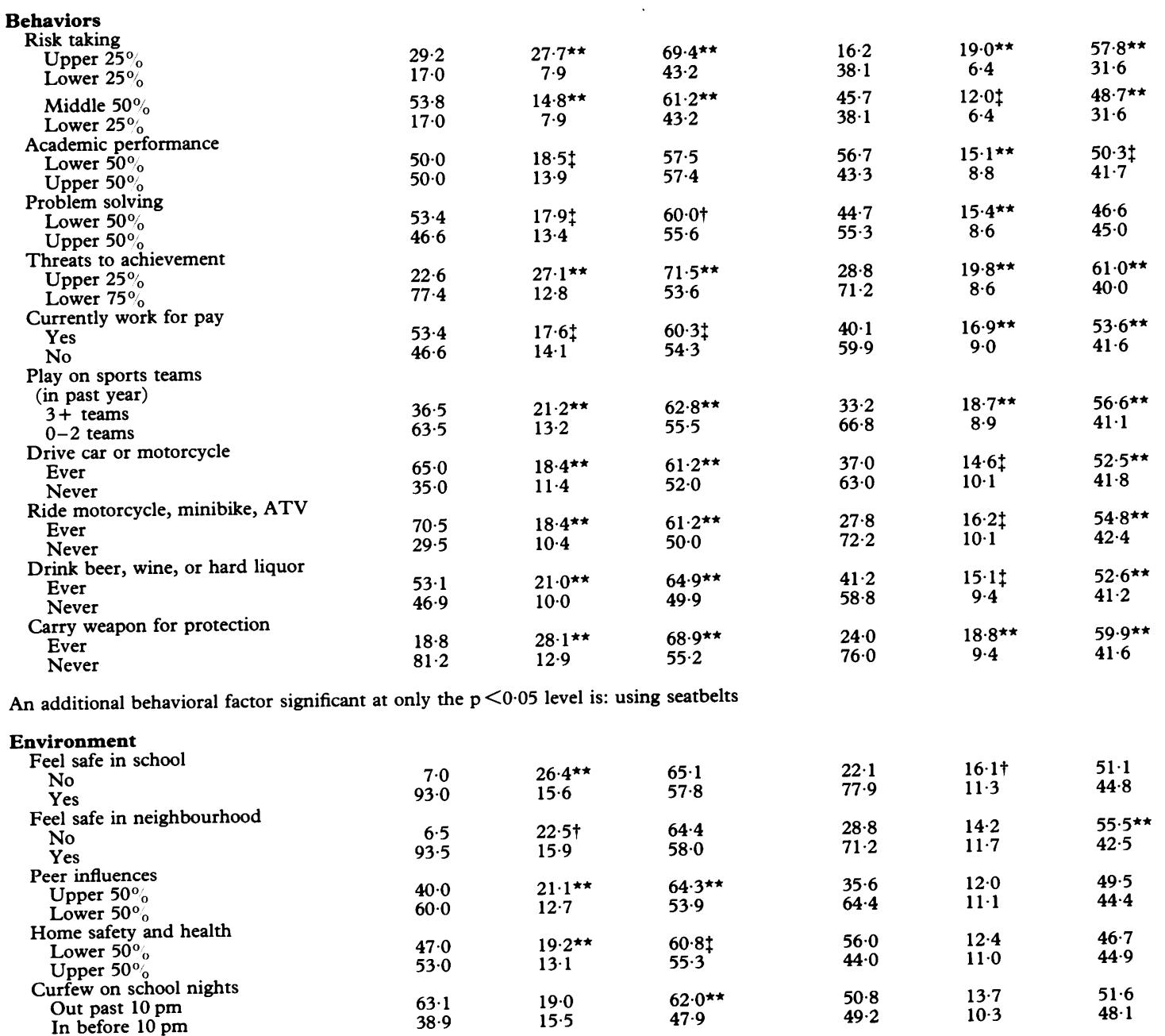

Additional environmental factors significant at only the $p<0.05$ level are: guns in the home and family involvement

*Only factors for which at least one comparison was significant at the $p<0.01$ level are presented.

tp $<0.10 ; \neq p<0.05 ; \star \star p<0.01$.

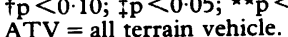


However, a different pattern is seen in the interaction effect for alcohol use and sports. The logistic regression coefficient for this interaction is negative, resulting in an odds ratio less than $1(0.39)$. This indicates that the risk modeled by the interaction is lower than would be expected by the simple multiplication of the main effects. So there appears to be modest protective effect for rural youth who

Table 4 Logistic regression results for major injury among urban and rural adolescents: main effects

\begin{tabular}{|c|c|c|c|c|}
\hline \multirow[b]{2}{*}{ Variable } & \multicolumn{2}{|c|}{ Rural $(n=1878)$} & \multicolumn{2}{|c|}{ Urban $(n=877)$} \\
\hline & Odds ratio & $95 \% C I$ & Odds ratio & $95 \% C I$ \\
\hline \multicolumn{5}{|l|}{ Demographics } \\
\hline \multicolumn{5}{|l|}{ Gender } \\
\hline Male & $2 \cdot 0 \ddagger$ & $(1 \cdot 4$ to $2 \cdot 6)$ & $3.3 \ddagger$ & $(1.7$ to 6.3$)$ \\
\hline $\begin{array}{r}\text { Female } \\
\text { Ethnicity }\end{array}$ & $1 \cdot 0$ & & 1.0 & \\
\hline \multicolumn{5}{|l|}{ Ethnicity } \\
\hline $\begin{array}{l}\text { White/other } \\
\text { Black }\end{array}$ & & & $2 \cdot 2 \ddagger$ & $(1.3$ to 3.8$)$ \\
\hline $\begin{array}{c}\text { Black } \\
\text { Behaviors }\end{array}$ & & & 1.0 & \\
\hline \multicolumn{5}{|l|}{ Behaviors } \\
\hline \multicolumn{5}{|c|}{ Drink beer, wine, hard liquor } \\
\hline $\begin{array}{l}\text { Ever } \\
\text { Never }\end{array}$ & $2 \cdot 9 \ddagger$ & $(1.7$ to 5.0$)$ & & \\
\hline \multicolumn{5}{|l|}{ Risk taking (percentile) } \\
\hline High (upper 25th) & $2.0 \dagger$ & $(1 \cdot 1$ to $3 \cdot 7)$ & & \\
\hline Other (lower 75 th) & 1.0 & & & \\
\hline \multicolumn{5}{|l|}{ Plays on sports team } \\
\hline $\begin{array}{c}\text { (in past year) } \\
3+\text { teams }\end{array}$ & & & & \\
\hline $\begin{array}{l}3+\text { teams } \\
0-2 \text { teams }\end{array}$ & & & $6 \cdot 3 \ddagger$ & $(2 \cdot 7$ to $14 \cdot 3)$ \\
\hline \multicolumn{5}{|c|}{ Carry a weapon for protection } \\
\hline Ever & & & $4.5 \ddagger$ & $(2 \cdot 3$ to $8 \cdot 3)$ \\
\hline Never & & & $1.0^{+}$ & \\
\hline \multicolumn{5}{|l|}{ Currently work for pay } \\
\hline Yes & & & $1.7 \dagger$ & $(1 \cdot 1$ to $2 \cdot 8)$ \\
\hline No & & & 1.0 & \\
\hline \multicolumn{5}{|c|}{ Environmental characteristics } \\
\hline Safe in school & & & & \\
\hline No & & & $2 \cdot 0 \ddagger$ & $(1 \cdot 1$ to $3 \cdot 3)$ \\
\hline Yes & & & $1 \cdot 0$ & \\
\hline
\end{tabular}

Table 5 Logistic regression results for major injury among urban and rural adolescents: interaction effects

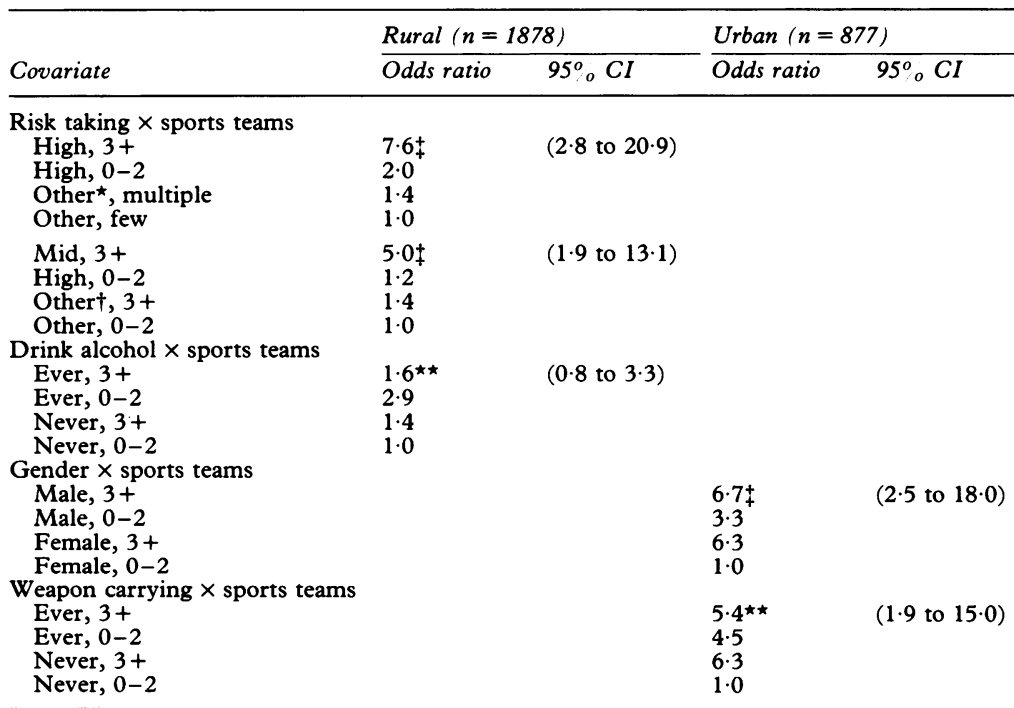

Note: Please refer to text for detailed explanation of how these odds ratios were obtained. A brief example of how to interpret the interactions using high risk taking and sports team participation in the rural sample follows: the reference group are the teens who do not exhibit high risk behaviors (other) and play on fewer than three sports teams $(0-2)$, and their odds ratio of incurring a major injury is set at 1.0 (both main effects are 1.0 ); in the absence of high risk behaviors the odds ratio for playing on three or more teams is $1.4(1.0 \times 1.4)$; those with high risk behaviors who play on fewer than three teams is $2.0(2.0 \times 1.0)$; finally, the odds ratio for the group with high risk behaviors that plays on three or more teams is determined by taking the product of the odds for each group and multiplying it by the interaction term $(2.0 \times 1.4 \times 2.7)$

$\star$ Refers to the contrasting group, comprising middle and low risk taking.

tRefers to the contrasting group, comprising high and low risk taking.

tp<0.05; ${ }^{\star \star} \mathrm{p}<0.01$.

$\stackrel{+\mathrm{p}}{\mathrm{CI}}=\mathbf{0}$ confidence interval. use alcohol if they play many sports. This is possibly because of the restrictions that serious sports participation places on alcohol use.

\section{Urban sample: major injury}

Among urban youth, the probability of major injury was approximately twice as high forthose who were white; worked for pay; or felt unsafe at school. Risk was five to six times greater for urban males who played a lot of sports and for those who both carried a weapon and played many sports, compared with those without either of these characteristics. The effect of the interactions, however, is somewhat unexpected. The odds ratio for both interactions is less than 1 , indicating that the combined effect of being on more than three sports teams and either being male or carrying a weapon, does not increase the risk of having at least one major injury, as much as would be expected by the combination of the main effects.

FACTORS RELATED TO MINOR INJURY IN MULTIVARIATE LOGISTIC REGRESSION ANALYSIS Many of the factors significant in major injury were also identified for minor injuries (tables 6 and 7). The most notable exception is male gender, which is not a predictor of minor injury in either site. In the rural sample, the main effects of risk taking, any use of alcohol, and high sports participation were associated with an increased risk of injury. One interaction reflects a greatly increased risk for rural youth who have both a doctor identified behavior disorder and are in the top quartile of the distribution on the antisocial behavior scale, threats to achievement. These youth had a risk of minor injury 9.4 times higher than those who have neither an identified behavior disorder or high level of antisocial behavior. Three individual characteristics significantly increased the risk of minor injury for urban youth: being white, having an emotional disorder, or any reduction in vision, as did feeling unsafe in one's neighborhood. The most powerful predictor was the interaction of antisocial behaviors (threats to achievement) and participation on sports teams, which greatly increased the risk of minor injury by a factor of 20 among urban youth.

\section{Discussion}

Injuries affected $53 \%$ and $65 \%$ of the youth in these urban and rural samples, respectively, with approximately one quarter of the youth incurring a major injury over the last year. Boys had higher rates than girls for all injuries, and this difference was most pronounced for major injuries consistent with national data. ${ }^{29}$ Although direct comparisons of the urban and rural samples were not undertaken because of the confounding of race and geographical location, there is a consistently higher rate of injury among the rural youth. Among the major injuries, this discrepancy is accounted for almost entirely by the much higher rate of 
Table 6 Logistic regression results for minor injury among urban and rural adolescents: main effects

\begin{tabular}{|c|c|c|c|c|}
\hline \multirow[b]{2}{*}{ Variable } & \multicolumn{2}{|c|}{ Rural $(n=1878)$} & \multicolumn{2}{|c|}{ Urban $(n=877)$} \\
\hline & Odds ratio & $95^{\circ}{ }_{o} C I$ & Odds ratio & $95 \% C I$ \\
\hline \multicolumn{5}{|l|}{ Demographics } \\
\hline \multicolumn{5}{|l|}{ Ethnicity: } \\
\hline White/other & & & $2 \cdot 0 \star \star$ & $(1.3$ to 3.1$)$ \\
\hline Black & & & $1 \cdot 0$ & \\
\hline \multicolumn{5}{|c|}{ Disorders and impairments } \\
\hline \multicolumn{5}{|c|}{ Behavior disorders } \\
\hline Ever & $2 \cdot 4^{\star \star}$ & $(1.3$ to 4.8$)$ & & \\
\hline Never & 1.0 & & & \\
\hline \multicolumn{5}{|c|}{ Emotional/mental disorder } \\
\hline Ever & & & $2 \cdot 3 \star \star$ & $(1 \cdot 2$ to $4 \cdot 3)$ \\
\hline \multirow{2}{*}{\multicolumn{5}{|c|}{ Vision impairment }} \\
\hline & & & & \\
\hline Yes & & & $1.5 \ddagger$ & $(1 \cdot 1$ to $2 \cdot 2)$ \\
\hline No & & & $1 \cdot 0$ & \\
\hline \multicolumn{5}{|l|}{ Behaviors } \\
\hline \multicolumn{5}{|l|}{ Risk taking (centile) } \\
\hline High (upper 25th) & $1 \cdot 9^{\star \star}$ & $(1 \cdot 4$ to $2 \cdot 6)$ & & \\
\hline Other ${ }^{\star}$ & $1 \cdot 0$ & & & \\
\hline Mid (middle 50th) & $1 \cdot 8^{\star \star}$ & $(1 \cdot 4$ to $2 \cdot 2)$ & & \\
\hline Othert & $1 \cdot 0$ & & & \\
\hline \multicolumn{5}{|l|}{ Threats to achievement } \\
\hline Upper $25^{\circ} \circ$ & $1 \cdot 8^{\star \star}$ & (1.3 to 2.4$)$ & $2 \cdot 7^{\star \star}$ & (1.8 to 4.2$)$ \\
\hline Lower $75^{\circ} \mathrm{o}$ & $1 \cdot 0$ & & $1 \cdot 0$ & \\
\hline \multicolumn{5}{|c|}{ Plays on sports teams (in past } \\
\hline $\begin{array}{l}\text { year) } \\
3+\text { teams }\end{array}$ & $1 \cdot 3+$ & $(1 \cdot 1$ to $1 \cdot 6)$ & $2 \cdot 0 \star \star$ & $(1.4$ to 3.0$)$ \\
\hline $0-2$ teams & $1.0^{+}$ & & $1 \cdot 0$ & \\
\hline \multicolumn{5}{|c|}{ Drink beer, wine, hard liquor } \\
\hline Ever & $1 \cdot 4^{\star \star}$ & $(1 \cdot 1$ to $1 \cdot 7)$ & & \\
\hline Never & $1 \cdot 0$ & & & \\
\hline \multicolumn{5}{|c|}{ Environmental characteristics } \\
\hline $\begin{array}{l}\text { Safe in neighborhood } \\
\text { No }\end{array}$ & & & & \\
\hline $\begin{array}{l}\text { No } \\
\text { Yes }\end{array}$ & & & $\begin{array}{l}1 \cdot 0^{* n} \\
1 \cdot 0\end{array}$ & $(1.1$ to $2 \cdot 2)$ \\
\hline
\end{tabular}

${ }^{\star}$ Refers to the contrasting group, comprising middle and low risk taking. + Refers to the contrasting group, comprising high and low risk taking.

${ }_{t}^{+} \mathrm{p}<0.05 ;{ }^{\star}{ }^{\mathrm{p}} \mathrm{p}<0.01$

$\stackrel{+}{\mathrm{CI}}=$ confidence interval.

Table 7 Logistic regression results for minor injury among urban and rural adolescents: interaction effects

\begin{tabular}{|c|c|c|c|c|}
\hline \multirow[b]{2}{*}{ Interaction effects } & \multicolumn{2}{|c|}{ Rural $(n=1878)$} & \multicolumn{2}{|c|}{ Urban $(n=877)$} \\
\hline & Odds ratio & $95 \% C I$ & Odds ratio & $95 \% C I$ \\
\hline $\begin{array}{l}\text { Threats } \times \text { behavior disorder } \\
\text { Upper } 25^{\circ} \text {, behavior disorder } \\
\text { Upper } 25^{\circ} \% \text {, no behavior disorder } \\
\text { Lower } 75^{\circ} \text {, behavior disorder } \\
\text { Lower } 75^{\circ} \text {, no behavior disorder }\end{array}$ & $\begin{array}{l}9 \cdot 4^{\star} \\
1 \cdot 8 \\
2 \cdot 4 \\
1 \cdot 0\end{array}$ & $(3.9$ to 22.6$)$ & & \\
\hline $\begin{array}{l}\text { Threats } \times \text { sports teams } \\
\text { Upper } 25^{\circ}, 3+ \\
\text { Upper } 25^{\circ}, 0-2 \\
\text { Lower } 75^{\circ}, 3+ \\
\text { Lower } 75^{\circ}{ }_{0}, 0-2\end{array}$ & & & $\begin{array}{c}20 \cdot 1 \dagger \\
2 \cdot 7 \\
2 \cdot 0 \\
1 \cdot 0\end{array}$ & (9.9 to 40.9$)$ \\
\hline
\end{tabular}

Please see explanatory note to table 5 for interpretation of odds ratios for these interaction effects. ${ }^{\star} \mathrm{p}<0.05 ; \mathrm{tp}<0.01$.

$\mathrm{CI}=$ confidence interval sports (64\% v 79\% respectively). By comparison, drinking rates among rural youth who have not suffered a major injury are $51 \%$ regardless of sports participation. Apparently, heavy participation in sports reduces the likelihood of drinking thereby reducing the associated risk of injury.

The interactions for major injury in the urban sample also appear counterintuitive because the combined risk of two characteristics is less than would be expected. That is, playing sports and carrying weapons each dramatically increase the risk of injury but when these factors are considered together the risk is not multiplied as much as expected. Generally, somewhat fewer than a third of urban youth report carrying a weapon, whether or not they incurred a major injury, with one exception: $49 \%$ of those with major injury who do not play multiple sports carry a weapon. Their risk of injury is quite high due to their weapons, but the risk among the group who both play a lot of sports and carry weapons is less. Playing team sports seems to offer some protection to youth who report carrying a weapon for protection, possibly by channeling aggressive behavior in more positive ways.

The other interaction in the urban sample is that of being a male and playing a lot of sports; this reflects a different phenomenon that may relate more generally to the role of gender in injury. The risk of major injury is similar for girls and boys with high participation (odds ratio 6.3 and $6 \cdot 7$, respectively), indicating that playing team sports poses comparable injury risk for both sexes. Sports team participation elevates the risk much more for girls than it does for boys, however, with injury rates in the urban sample of girls increasing from $4.8 \%$ among those without much sports participation, to $16.0 \%$ for those on many teams. Based on these data, the unexplained gender difference in risk of major injury is primarily for youth who do not participate in many sports.

Gender differences in major injury may also result from the fact that, in general, girls and boys have distinct cognitive styles regarding risk perception. Girls perceive significantly greater risks than boys when given tasks such as ranking the danger associated with certain behaviors or situations, ${ }^{30}$ a difference that increases with increasing age. On urban sports teams there is high risk for both sexes. However, among youth who do not play many sports, girls may more actively avoid risk situations than boys. Additional understanding of the effect of gender on injury is provided by the fact that the differential risk of minor injury observed for boys in the bivariate analyses was completely explained by the various individual and behavioral factors in the multivariate analysis performed for minor injuries. Indeed, we see in the data that the factors that predict minor injury are more common in boys.

It is puzzling that we did not find a difference in injury rates by age, in either site. Nationally, higher injury rates for older teens are thought to be associated with driving. However, only one third of the urban youth report ever driving major injury. However, youth with a major injury who play on multiple sports teams are less likely to drink than those who play few 
a car, perhaps explaining the lack of an age effect there. Among the rural youth, on the other hand, two thirds drive, with $80 \%$ of the oldest teens reporting they drove in the past month.

In both samples, the prevalence of major injury was significantly higher among adolescents who worked, although in the multivariate analyses this exposure characteristic was retained only for the urban youth. Others have found that students who work (more than 10 hours a week) are significantly more likely to report a medically attended injury in the past year. ${ }^{1531}$

As shown in table 3, the rate of major injury in the urban site was twice as high among the white population as among the black, AfricanAmerican group. Minor injuries were also significantly higher among the white youth. These patterns are consistent with national data, ${ }^{322}$ and limit the ability to make direct comparisons between the predominantly white rural sample and the mixed race urban sample in this study. The usual explanations that race effects on injury reflect socioeconomic differences in access to vehicles or recreational activities do not seem to hold here, because socioeconimic factors were not significantly related to injury rates and they were controlled for in all multivariate analyses. More detailed research is needed to examine the cultural and contextual mechanisms associated with these racial differentials. ${ }^{32}$

Interpretation of this study is limited in certain ways. First, the samples are drawn from specific schools in the mid-Atlantic region and the results pertain only to youth still attending school. The 1992 National Health Interview Survey (NHIS) showed that adolescents who have dropped out of school are significantly more likely to engage in risk behaviors such as driving with a drinking driver, participating in a fight, or carrying a weapon..$^{33}$ Second, although these samples represent these schools well, and the respective schools represent the city and county well, they do not constitute population based samples that can be used to estimate true prevalence rates.

A third consideration relates to the interpretation of all injury rate data. The rural and urban rates are consistent with the upper and lower rates of the NHIS ${ }^{3}$ data despite the major differences in methods between the surveys. This may be explained by the presence of countervailing effects. The NHIS recall period of two weeks overinflates reports of injuries that required medical treatment or a reduction in usual activities. ${ }^{23}$ An annual recall, as used here, results in under-reporting, especially of minor injuries. However, in this study all injuries that the adolescent could recall are included, whether or not they were medically treated or resulted in a reduction of activities, thus increasing the reported injury rate.

Although the analysis of the 1988 NHIS Child Health Supplement indicates that minor injuries were not differentially recalled based on whether they had resulted in a physician visit, ${ }^{23}$ we found a regular source of medical care to be associated with the number of minor injuries reported by both urban and rural youth. ${ }^{26}$ As discussed, significantly fewer rural youth had a regular source of medical care, and although they had the highest rate of minor injuries, they also had a lower rate of medically treated minor injuries. Reports of minor injuries are most likely to be biased by medical accessibility, as treatment is more discretionary. In general, major injuries are the most likely to be reported accurately..$^{22} 2335$ Although each method of recall has specific effects on rates, it is important to note that the CHIP$\mathrm{AE}^{\mathrm{tm}}$ items are worded to elicit injuries of consequence, for example 'bad cut' and 'bad sprain' and that the annual reports in this study were shown to have good test-retest reliability. Moreover, the accuracy of adolescent recall of injury does not appear to be very different from that of adults. ${ }^{36}$ The effect of recall errors are moderated in this study because if a youth had at least one minor or major injury, he/she would be included in the appropriate analyses. Approximately two thirds of injuries categorized as major were treated by a physician or nurse, as were one third of the minor injuries.

Finally, the data are cross sectional. Ideally, risk factors would be assessed before injury occurrence to provide more assurance that the causal sequence is as implied in these analyses.

\section{Implications for prevention}

This investigation highlights the influence of adolescents' behavior and their environments on the probability of injury. Parents, teachers, coaches, and other adults need to communicate specific behavioral messages to teens, including the concept that injuries are not 'accidents'. ${ }^{37}$ For example, teaching teens to designate a sober driver is more likely to be effective than the usual admonition to 'drive safely'. As discussed earlier, an integrative view of prevention, such as that provided by Gielen, ${ }^{17}$ is needed. Her work, based on a combination of traditional countermeasures and health education models, provides an integrative planning framework for interventions that incorporate both non-behavioral factors (legal, technical, engineering) and behavioral factors. Our analysis underscores the need for and potential effectiveness of such targeted interventions. Only two adolescent injury reduction programs have been reported and both targeted environmental as well as behavioral change. ${ }^{38} 39$ They achieved modest reductions in the incidence of injuries, indicating both the challenge and the opportunity of such efforts. The behavior change techniques that work predictably at the individual level have rarely been systematically transferred to large scale situations, although the means exist to do so and population changes in smoking, diet, and exercise habits suggest the potential for making similar changes in injury occurrence. ${ }^{40}$ Despite a reduction in injury deaths among youth over the past two decades, ${ }^{41}$ we are still confronted with the fact that injuries remain the leading cause of senseless mortality among the young, as well as with the reality that adolescent 
behavior is a critical factor in the injury equation. It must be incorporated in the development of any systematic, multifaceted approach to injury reduction.

The assistance of the city and county school district personnel, administrative staff, teachers, and students is sincerely appadministrative staff, teachers, and students is sincerely appreciated. The contribution of staff in the school health program of the Univefuly acknowledge the project management efforts of Kelly
Vogel Crawford; Wanda Adams' clerical support; and the data Vogel Crawford; Wanda Adams' clerical support; and the data analytic support provided by Mia Kang, MS, and Dennis
Johnston, MS. The thoughtful comments of the two anonymous Johnston, MS. The thoughtful comment

reviewers are also much appreciated.

Source of support: this research was supported in part by the Agency for Health Care Policy and Research, grant No HS07405 and by the Bureau of Maternal and Child Health, HHS, grant No MCJ 247307 .

1 Runyan CW, Gerken EA. The health of adolescents. Injuries. In: Hendee WR, ed. San Francisco, CA: Jossey-Bass 1991: 302-33.

2 Anonymous. Status of ' 90 objectives targets concerns for year 2000. Target $20001991 ; 2$ (3).

3 US National Center for Health Statistics (NCHS). Current estimates from the national health interview survey, 1991. DHHS Publication No (PHS) 93-1512. Hyattsville, MD: US DHHS. Vital and Health Statistics, 1992a; 10(184).

4 Rice DP, MacKenzie EJ and Associates. Cost of injury in the United States. A report to Congress. San Francisco, CA: Institute for Health and Aging, University of California Institute for Health and Aging, Univers

5 Gallagher SS, Finison K, Guyer B, Goodenough S. The Incidence of injuries among 87000 Massachusetts children and adolescents: results of the 1980-1981 statewide ren and adolescents: results of the $1980-1981$ statewide
childhood injury prevention program surveillance childhood injury prevention program surve
system. Am $\mathcal{F}$ Public Health 1984; 74: 1340-7.

6 US National Center for Health Statistics (NCHS). National ambulatory medical care survey: 1989 summary. DHHS Publication No(PHS) 92-1771. Hyattsville, MD: US DHHS. Vital and Health Statistics, 1992b; 13(110).

7 Runyan CW, Gerken EA. Epidemiology and prevention of adolescent injury. $\mathcal{F} A M A 1989 ; 262$ : 2273-9.

8 Kearney PA, Stallones L, Swartz C, Barker DE, Johnson SB. Unintentional injury death rates in rural Appalachia. f Trauma 1990; 30: 1524-32.

9 Greenberg MR, Carey GW, Popper FJ. Violent death, violent states, and American youth. Public Interest 1987; 87: $38-48$.

10 Runyan CW, Kotch JB, Margolis LH, Buescher PA. Childhood injuries in North Carolina: a statewide analysis of hospitalizations and death. Am F Public Health 1985; 75: $1429-32$.

11 Castillo DN, Landen DD, Layne LA. Occupational injury deaths of 16-and 17-year-olds in the United States. $\mathrm{Am} \mathcal{F}$ Public Health 1994; 84: 646-9.

12 Rivara FP. Fatal and nonfatal farm injuries to children and adolescents in the United States. Pediatrics 1985; 76 567-73.

13 Advocates for Children and Youth. Kids count fact book. Baltimore, MD: Advocates for Children and Youth Inc, 1993.

14 Blyth DA, Roehlkapartain EC. Healthy communities, healthy youth. Minneapolis, MN: Search Institute, 1993.

15 Alexander CS, Ensminger ME, Somerfield MR, Kim YJ, Johnson KE. Behavioral risk factors for injury among Johnson KE. Behavioral risk factors for injury amon

16 Alexander CS, Somerfield MR, Ensminger ME, Kim YJ, Johnson KE. Gender differences in unintentional injuries among rural youth. Injury Prevention 1995; 1: 15-20.

17 Gielen AC. Health education and injury control: integrating approaches. Health Educ $Q$ 1992; 19: 203-18.

18 US Bureau of the Census. Brief economic facts. Maryland: Maryland Office of Planning, 1991.
19 Starfield B, Bergner M, Ensminger ME, et al. Adolescent health status measurement: the development of CHIP. Pediatrics 1993; 91: 430-5.

20 Starfield B, Riley AW, Green BF, et al. The adolescent child health and illness profile: a population-based measure of health. Med Care 1995; 33: 553-66.

21 Committee on Injury Scaling, American Association for Automotive Medicine. The abbreviated injury scale, 1985 revision. Chicago, Illinois: AAAM, 1985

22 Scheidt PC, Harel Y, Trumber AC, Jones DH, Overpeck $\mathrm{MD}$, Bijur PE. The epidemiology of nonfatal injuries among US children and youth. Am $\mathcal{F}$ Public Health 1995; 85: $932-8$.

23 Harel Y, Overpeck MD, Jones DH, et al. The effects of recall on estimating annual nonfatal injury rates for children and adolescents. Am f Public Health 1994; 84: 599-605.

24 Cohen J. A coefficient of agreement for nominal scales. Educational and Psychological Measurement 1960; 20: 37-45.

25 Fleiss JL. Statistical methods for rates and proportions. 2nd Ed. New York: Wiley and Sons, 1981.

26 Riley AW, Alexander C, Ryan S, et al. Characteristics associated with medically treated and non-treated injury among urban and rural adolescents. Presentation to the Injury Control and Emergency Health Services Section. American Public Health Association, San Francisco, CA: October 1993.

27 Alexander CS, Kim YJ, Ensminger ME, Johnson KE, Smith BJ, Dolan LJ. A measure of risk taking for young adolescents: reliability and validity assessments. $\mathcal{f}$ Youth Adolesc 1990; 19: 559-69.

28 Kleinbaum DG, Kupper LL, Muller KE. Applied regression analysis and other multivariable methods. 2nd Ed. Boston, MA: PWS-Kent Publishing, 1988.

29 Centers for Disease Control. Behaviors related to unintentional and intentional injuries among high school students

30 Irwin CE, Jr, Millstein SG. Correlates and predictors of risk-taking behaviors during adolescence. In: Lipsitt LP, Mitnick LL, eds. Self regulatory behavior and risk-taking: causes and consequences. Norwood NJ: Ablex Inc, 1991: $3-21$.

31 Bass JL, Gallagher SS, Mehta KA. Injuries to adolescents and young adults. Pediatr Clin North Am 1985; 32: 31 -9.

32 LaVeist TA. Beyond dummy variables and sample selection: what health services researchers ought to know about race as a variable. Health Serv Res 1994; 29: 1-16.

33 National Education Goals Panel. The national education goals report. Washington, DC: National Education Goals Panel, 1991.

34 Centers for Disease Control and Prevention. Health risk behaviors among adolescents who do and do not attend school - United States, 1992. Morbidity and Mortality Weekly Report. Atlanta: Centers for Disease Control and Prevention, 1994.

35 Peterson L, Harbeck C, Moreno A. Measures of children's injuries: self-reported versus maternal-reported events with temporally proximal versus delayed reporting. $f$ Pediatr Psychol 1993; 18: 133-47.

36 Langley JD, Cecchi JC, Williams SM. Recall of injury events by thirteen year olds. Methods Inf Med 1989; 28: 24-7.

37 Langley JD. The need to discontinue the use of the term 'accident' when referring to unintentional injury events. Accid Anal Prev 1988; 20: $1-8$.

38 Davidson LL, Durkin MS, Kuhn L, O'Connor P, Barlow B, Heagarty MC. The impact of the safe kids/healthy neighborhoods injury prevention program in Harlem, neighborhoods injury prevention program in Harlem,

39 Guyer B, Gallagher SS, Chang B, Azzara CV, Cupples LA Colton T. Prevention of childhood injuries: evaluation of Colton T. Prevention of childhood injuries: evaluation of
the statewide childhood injury prevention program the statewide childhood injury prevention prog
(SCIPP). Am F Public Health 1989; 79: 1521-7.

40 DHHS. Healthy people 2000: national health promotion and disease prevention objectives. (Full report, with commentary.) Public Health Serive (DHHS/PHS \#91-50212.) Washington DC: US DHHS, 1992.

41 Singh GK, Yu SM. US childhood mortality, 1950 through 1993: trends and socioeconomic differentials. Am $\mathcal{F}$ Public Health 1996; 86: 505-12.

\section{Airbags of the future}

An article about airbag hazards predicts that 'eventually ... cars will come equipped with an airbag that switches off automatically if no one is occupying the passenger seat or adjusts to match the height of the seat's occupant'. It quotes Tim Hurd, spokesman of the National Highway Traffic Safety Administration, as advising, 'Until then the safest place for the child is in the back seat, all buckled up' (Time, 24 June 1996).

\section{Tainted mettwurst}

An Australian newspaper article reported that three former company directors were charged with the manslaughter of a 4 year old girl who died after eating contaminated mettwurst. The lawyer acting on behalf of the dead girl's family said the decision heralded 'a new era of accountability'. Twenty two other children were affected by the outbreak of haemolytic uraemic syndrome that followed the eating of the product (The Age, 21 February 1996). 